\title{
Thematic Contrasts of Ed.D. and Ph.D. Dissertations
}

\author{
Kathleen Taylor Campbell \\ Professor \\ Department of Educational Leadership \& Technology \\ Southeastern Louisiana University \\ SLU 549, Hammond, LA 70402, USA \\ Thomas DeVaney \\ Department Head \\ Department of Educational Leadership \& Technology \\ Southeastern Louisiana University \\ SLU 549, Hammond, LA 70402, USA
}

\begin{abstract}
One of the goals of the educational leadership doctoral degree is to prepare leaders to develop solutions to problems and to conduct research affecting educational policy. Despite rigorous coursework, research, analysis, and writing, some have criticized the doctoral dissertation process in education. The purpose of the present study was to analyze recent dissertations in educational leadership and to identify common themes by examining titles, abstracts, statements of purpose, and problem statements for relevance to the field of education. The researchers further investigated whether or not there were differences between Ed.D. and Ph.D. dissertations. Although both emphasized principal leadership, the Ed.D. dissertations focused more on leadership styles while Ph.D dissertations focused more on leadership development and behavior. Ed.D. dissertations had a slight tendency to be more focused on K-12 practical problems while the Ph.D. dissertations had a slight tendency to be more focused on higher education and theory.
\end{abstract}

Keywords: educational leadership/administration, dissertations, dissertation themes, Ed.D., Ph.D., education doctorates

\section{Objectives}

The major goals of colleges of education are to advance knowledge and to prepare quality practitioners (Schulman, Golde, Bueschel, \& Garabedian, 2006). It is only fitting, therefore, that one of the chief objectives of the educational leadership Ed.D. degree is to prepare school and district leaders who can perform research that will affect policy (Hanna, 2015). To that end, educational doctoral programs should train the doctoral candidates "to address problems and develop solutions" (Kidwell et al, 2010, p. 14). Indeed, those who receive Ed.D. degrees are put into practitioner roles to "solve critical problems, expand the boundaries of knowledge, teach future generations, and provide leadership" (Danowitz, Spires, Clark, Faircloth, Fleener, Lee, \& McIntyre, 2015, p. 3). Educational doctoral programs strive for high expectations, requiring the completion of rigorous coursework, demanding research, and thorough analysis and writing; yet some critics continue to disparage the doctoral dissertation process (Archbald, 2008; Boote \& Beile, 2005, 2004; Shulman, 2010) and education doctoral programs in general (Walker et al, 2008).

Some of the areas of criticism can be summarized by the following questions on which critics continue to concentrate. Are education dissertations relevant? Do the education dissertations study important matters in the field of education and/or educational leadership? Do they actually add to the body of knowledge in a meaningful way to education? Or are they merely projects that provide concrete evidence of the doctoral candidate's ability to conduct research or analyze critically? And is there a difference between the Ed.D. and the Ph.D. programs? Is there a difference between the Ed.D. and the Ph.D. dissertations?

The purpose of the present study was to analyze dissertation topics, abstracts, and statements of purpose and significance of study statements for indications of relevance and/or advancement in the field of education. The researchers scanned dissertations completed in 2015 at universities in the United States and searched for relevance, problem solutions, critical inquiry, or personal interest. The differences between the Ed.D. and the Ph.D. dissertations are presented and the criteria by which the categories are defined are described. 


\section{Brief Literature Review}

Boote and Beile (2004) were two researchers who were dissatisfied with the inadequate quality of the literature review in numerous dissertations. Consequently, they published a 12-point rubric to evaluate the quality of the dissertation literature review, insisting that important and meaningful research must follow from the firm foundation of a substantive and thorough literature review. The rubric included the criteria such as coverage, synthesis, methodology, significance, and rhetoric. Some criteria were further subdivided. For example, significance was broken down into the subgroups of practical and scholarly significance, and methodology was broken down into the subgroups of main methodologies as well as ideas and theories. The following year, Boote \& Beile (2005) continued to complain about the poor quality of the literature review in many dissertations. They alleged that doctoral candidates often are neither trained nor prepared for serious reviews of the literature before they actually begin the process of writing the dissertation. They noted Creswell's (1994) premise that the literature review's purposes are to indicate what has already been done regarding the topic, to extend or replicate what has already been done, and to provide a framework for establishing the importance of the study.

The importance of the dissertation and its literature review was also emphasized by other researchers. Onwuegbuzie and Frels (2016) observed that the sharing of knowledge in the social sciences is the "driving force for advances in the field" (p. xii). They further maintained that "a lack of awareness of existing knowledge might lead us to utilize practices that have been found previously to be ineffective" (p. 3) and stated that a review of the literature is one means of determining what has already been done in the field. Randolph (2009) contended that the entire dissertation could simply be derailed by a poor literature review. He further compared the stages of the literature review (secondary research) process with the stages of primary research, claiming that the units of analysis in the literature review are the articles reviewed rather than the human subjects in primary research. Moreover, validity and reliability are necessary in primary research and in literature reviews (pp. 4-5). Gamoran (2007) declared that exemplary dissertations include the five qualities of originality, rigor, relevance, contribution to disciplinary knowledge, and clarity of expression.

While critics may have highlighted the shortcomings of the dissertation and/or its literature review (Boote \& Beile, 2005), they did not contest the need for either. Some critics, on the other hand, questioned the necessity of a dissertation at all. Archbald (2008) disputed the need for a dissertation for the Ed.D. practitioner degree, although he recognized the firmly entrenched tradition of requiring a dissertation for a doctoral degree. As a solution, he recommended a new type of practitioner dissertation, a kind of Ed.D. thesis that would contain the qualities of "(a) developmental efficacy, (b) community benefit, (c) intellectual stewardship, and (d) distinctiveness in form and function" (p. 705). Others cast doubts on the academic value of an educational doctoral program. Walker et al (2008) stated that such programs have issues of "purpose, vision, and quality" (p. 3).

Others criticized the lack of distinction between Ph.D. and Ed.D. programs. Schulman et al (2006) asserted that the Ed.D. and the Ph.D. degrees were supposed to occupy "overlapping yet distinct" (p. 26) areas of focus - the Ed.D. for practitioner preparation and the $\mathrm{Ph} . \mathrm{D}$. for the realm of academe. They complained that the two programs were too similar to be considered distinct. "Instead of having two separate entities...we have ... a blurring of boundaries, resulting in the danger that we achieve rigorous preparation neither for practice nor for research" (p. 26). They proposed retaining the $\mathrm{Ph} . \mathrm{D}$. degree and starting a new practitioner doctoral degree, the Professional Practitioner Doctorate, or P.P.D. The new P.P.D. would be "an extremely demanding, rigorous, respectable, high level academic experience" preparing students to be educational practitioners (p. 29).

Goldring and Schuermann (2009) detailed the changing context in the field of education that necessitated the redesign of educational doctoral programs to prepare educational leaders to meet the evolving challenges. These challenges include increased accountability, learner-centered leadership, data-based decision-making, school choice, and community engagement. "The growing complexity of educational leadership merits a program that is tailored to the preparation of leaders who are able to utilize a vast array of skills to provide sound educational experiences for those they serve" (p. 21).

Shulman (2010) blamed the educational doctoral programs for the lack of originality and creativity in their dissertation research, declaring "We do not subject our programs to the kinds of experimental, skeptical, adventurous innovations and tests that we claim to value in our scholarly work" (p. 13). Danowitz, Spires et al (2015) praised North Carolina State University's plan to revitalize its College of Education doctoral program. They predicted that it would lead to the production of a scholar leader prepared "to lead and influence policy decisions at the local, state, national, and international levels to solve the grand challenges of education" (p. 5). In the past decades of criticism of educational doctoral dissertations and programs, researchers have conducted various analyses. 
They have performed citation analyses of dissertations (MacRoberts \& MacRoberts, 2010; Haycock, 2004), compared the differences between Ed.D and Ph.D. dissertations (Nelson \& Coorough, 1994), and investigated criteria for practice-based Ph.D. dissertations (Winter, Griffiths, \& Green, 2000).

However, no one has investigated the thematic relevance of the educational leadership dissertations or the intentions of their authors to attempt to solve important and current problems in education. That is what this paper will present.

\section{Methods}

The present researchers examined titles and abstracts as well as the statements of the problem and/or significance and/or purpose of the study. From the examination the researchers identified common themes that were the focus of educational leadership dissertations completed in 2015. The researchers also scrutinized the dissertations, attempting to discover current relevance or practicality of the problem. Furthermore, the results were disaggregated by degree type (Ed.D or Ph.D), similarities and differences between the two types of dissertation were indicated, and the odds of one type over another for addressing a particular theme, issue, or problem were indicated.

\section{Data Sources}

Dissertations were identified and retrieved through the Proquest Dissertation and Thesis database using the following parameters: (a) subject descriptor $=$ educational leadership, (b) language $=$ English, (c) date range $=$ January 2015 to December 2015, and (d) full-text available. To export the necessary information (i.e., degree type and institution), the records were exported as text files. Further, because all records could not be saved as a single file, 50 records were saved per file. The text files were then modified using the Find and Replace function of Microsoft Word to create delimited files that were imported into Microsoft Excel. The imported files were merged to create a single Excel file that contained the information for all 2,029 records. This file was further modified by inserting a top row that contained variable labels that were used when the file was imported into SPSS for analysis.

Although the information included in each dissertation citation included the name of the institution at which the dissertation was completed, the Carnegie classification and type of institution was not available. Therefore, the dissertation file was merged with a data file that was available from the Integrated Postsecondary Data System (IPEDS). To merge the dissertation data with the IPEDS data, a column was added to the dissertation data file that contained the institution's IPEDS/Federal ID code. After this column was added, the files were merged in SPSS version 23 using the IPEDS/Federal ID code as the matched variable.

Of the 2,029 dissertations, 1,433 were identified as Ed.D. and 569 were identified as Ph.D. dissertations. Remaining dissertations were completed for degrees such as the Doctor of Business Administration, Doctor of Psychology, and Doctor of Professional Studies. For this research only dissertations associated with an Ed.D. or Ph.D. program were included. Therefore, the final population of dissertations from which the sample was selected included 2,002 dissertations. Using guidelines by Krijcie and Morgan (1970), 400 dissertations were selected from the population. Further, to provide sufficient representation within each degree type, the sample included 200 randomly selected Ed.D. and 200 randomly selected Ph.D. dissertations. An initial review of the selected dissertations suggested that all dissertations were not directly related to educational leadership/administration based on the inclusion of terms such as leadership or administration or positions such as leader, principal, or administrator. Based on these criteria, the researchers identified 100 Ed.D. and $100 \mathrm{Ph} . \mathrm{D}$. dissertations.

\section{Procedures}

Initially the researchers examined the title and abstract of each dissertation, and then they searched either the problem statement or the statement of significance or the purpose of the study statement to determine the relevant themes addressed in the dissertation. Inductive-based open coding of the initial iteration revealed 24 categories or themes for Ed.D. dissertations and 19 categories or themes for Ph.D. dissertations. Axial coding was used to combine similar categories in each type of dissertation, and the final iteration revealed 17 themes for Ed.D. and 14 themes for Ph.D. dissertations. Additionally, an odds ratio analysis was performed to determine the likelihood of one type of dissertation (Ed.D. or Ph.D.) or the other as addressing a particular theme or issue or problem.

\section{Results}

Dissertations were disaggregated by degree type (Ed.D. or Ph.D.). Common themes were identified, and the Ed.D. and $\mathrm{Ph} . \mathrm{D}$. dissertations were compared for similarities and differences of themes and then investigated for relevance to the field of educational leadership. They were further coded into deductive-based categories of intellectual, practical, or personal significance. Results were displayed as descriptive statistics. Common themes included principal leadership, ethnicity, efficacy, safety/bullying, culture/climate, gender, special education, higher education, and other kinds of schools (private, Catholic, charter, etc.). 
Themes that were specific to Ed.D. dissertations included classroom teaching strategies, professional development/PLCs, rural schools, poverty, evaluations, legal issues, online learning, and parental involvement. Themes that were specific to Ph.D. dissertations included teachers, theory, change, superintendents, and counselors.

Although there were common themes, the frequency often varied between the two types of dissertations. For example, higher education was the focus in 16 Ph.D. dissertations but in only three Ed.D. dissertations. This resulted in an odds ratio (OR) of 5.33, which indicates that a dissertation focused on higher education was 5.33 times more likely to appear in a Ph.D. dissertation than in an Ed.D. dissertation. Special education was the focus in nine Ed.D. dissertations but in only two $\mathrm{Ph} . \mathrm{D}$. dissertations $(\mathrm{OR}=4.5)$, which indicates that a special education dissertation was 4.5 times more likely to appear in an Ed.D. dissertation than in a Ph.D. dissertation. Finally, ethnicity was the focus in 14 Ed.D. dissertations but in only four Ph.D. dissertations $(\mathrm{OR}=3.5)$, which indicates that ethnicity was 3.5 times more likely to appear in an Ed.D. dissertation than in a Ph.D. dissertation.

In addition to the differences in major themes, subthemes of several common themes varied in frequency. For example, the subtheme of leadership styles under the principal leadership theme was found in 23 Ed.D. dissertations but in only $10 \mathrm{Ph} . \mathrm{D}$. dissertations. Although the OR associated with Principal Leadership in Ph.D. and Ed.D. dissertations resulted in an $\mathrm{OR}=1.21$, leadership style was 2.77 times more likely to appear in an Ed.D. dissertation that focused on Principal Leadership compared to the Ph.D. dissertations. Conversely, the subtheme of principal behaviors was identified in nine Ph.D. dissertations but in only four Ed.D. dissertations and resulted in an OR $=1.87$, suggesting that a focus on principal behaviors was more likely to appear in Ph.D. dissertations compared to Ed.D. dissertations. (See Table 1.)

Regarding the types of significance indicated in the dissertation, Intellectual/academic significance was found in 63 Ph.D. dissertations and 51 Ed.D. dissertations $(\mathrm{OR}=1.24)$. Practical significance was found in 79 Ed.D. dissertations and $64 \mathrm{Ph} . \mathrm{D}$. dissertations (OR = 1.23). These odds ratios suggest there is little difference between Ph.D. and Ed.D. dissertations concerning identified types of significance associated with dissertations. Although intellectual/academic and practical significance was frequently identified, personal significance was found in only one Ph.D. dissertation and was not found in any Ed.D. dissertations. The researchers regard this final fact to be counter intuitive because it has been our experience that dissertation topics are usually chosen by doctoral students because they find the problem, situation, or issue to be interesting or important to them, their school, or their occupation; however, only one of the 200 dissertations claimed a personally significant interest in the topic.

In conclusion, although there were many common themes and some that were specific to Ed.D. or Ph.D. dissertations, the researchers found the Ed.D. dissertations had a slight tendency to be more focused on K-12 practical problems while the Ph.D. dissertations had a slight tendency to be more focused on higher education and theory.

\section{Significance of the Study}

The results show that the Ed.D. dissertations are more likely to concentrate on practical K-12 problems while the Ph.D. dissertations are more likely to concentrate on higher education. This kind of information may assist school districts in identifying serious candidates who graduated from Ed.D. programs to be considered for positions such as school principal or school district superintendent because these graduates will have the ability to conduct research to affect policy for school improvement, thus helping public K-12 education. On the other hand, universities may be more interested in graduates of Ph.D. programs for their ability to conduct research in higher education problems and issues and for their theoretical bent. 


\section{Table 1. Frequency of Dissertation Themes}

Ed.D. Dissertations $(n=100)$

Ph.D. Dissertations $(n=100)$

\begin{tabular}{lclc}
\hline Variable & Frequency & Variable & Frequency \\
\hline Principal Leadership & 34 & Principal Leadership & 41 \\
\multicolumn{1}{c}{ Leadership styles } & 23 & Leadership styles & 10 \\
\multicolumn{1}{c}{ Principal behaviors } & 4 & Principal behaviors & 9 \\
\multicolumn{1}{c}{ Miscellaneous } & 2 & Principal traits & 4 \\
& 5 & Leader development & 7 \\
Teaching Strategies & 22 & Miscellaneous & 11 \\
Professional Dev/PLCs & 14 & Teachers & 12 \\
Ethnicity & 14 & Ethnicity & 4 \\
Efficacy & 9 & Efficacy & 6 \\
SPED/Inclusion & 9 & SPED & 2 \\
School Safety/Bullying & 5 & School Safety/Bullying & 4 \\
Gender & 3 & Gender & 8 \\
Higher Education & 3 & Higher Education & 16 \\
School Culture/Climate & 5 & School Culture/Climate & 3 \\
Rural Schools/Districts & 4 & Theory & 3 \\
Legal Issues & 4 & Change & 2
\end{tabular}

\section{References}

Archbald, D. (2008). Research versus problem solving for the educational leadership doctoral thesis: Implications for form and function. Educational Administration Quarterly, 44(5), 704-739.

Boote, D., \& Beile, P. (2005). Scholars before researchers: On the centrality of the dissertation literature review in research preparation. Educational Researcher, 34(6), 3-15.

Boote, D .N., \& Beile, P. (2004, April). The quality of dissertation literature reviews: A missing link in research preparation. Paper presented at the annual meeting of the American Educational Research Association, San Diego, CA

Creswell, J. W. (1994). Research design: Qualitative \& quantitative approaches. Thousand Oaks, Calif: Sage Publications.

Danowitz, M., Spires, H., Clark, A., Faircloth, S., Lee, H., \& McIntyre (Oct. 2015). Imagining the future of doctoral education: The scholar leader. NC State University College of Education Stimulus Paper. Retrieved from https://ced.ncsu.edu/wp-content/uploads/2015/11/Revised-Stimulus-Paper-10.16.15.pdf

Gamoran, A. (June, 2007). Reflections on exemplary dissertations in education research. Exemplary Dissertation Award Committee. Chicago, IL: Spencer Foundation https://www.spencer.org/reflections-exemplarydissertations-education-research

Goldring, E., \& Schuermann, P. (2009). The changing context of K-12 education administration: Consequences for Ed.D. program design and delivery, Peabody Journal of Education, 84(1), 9-43. Doi: $10.1080 / 01619560802679583$

Hanna, Jessica M., "The quality of education leadership doctoral dissertations in the United States: An empirical review" (2015). Theses, Dissertations and Capstones. Paper 961.

Haycock, L. A. (2004). Citation Analysis of Education Dissertations for Collection Development. Library Resources \& Technical Services, 48(2), 102-106.

Kidwell, C., Flagg, C., \& Stites-Doe, S. (2014). Graduate school and you: A guide for prospective students. Washington, D.C.: Council of Graduate Schools.

Krijcie, R. V., \& Morgan, D. W. (1970). Determining sample size for research activities. Educational and Psychological Measurement, 30, 607-610. 
MacRoberts, M. H., \& MacRoberts, B. R. (2010). Problems of citation analysis: A study of uncited and seldom-cited influences. Journal of The American Society For Information Science \& Technology, 61(1), 1-12. doi:10.1002/asi.21228

Nelson, J., \& Coorough, C. (1994). Content analysis of the PhD versus EdD dissertation. Journal of Experimental Education, 62(2), 158.

Onwuegbuzie, A. J., \& Frels, R. (2016). 7 steps to a comprehensive literature review: A multimodal and cultural approach. Los Angeles, CA: Sage.

Randolph, J. J. (June, 2009). A guide to writing the dissertation literature review. Practical Assessment, Research \& Evaluation, 14(13), 1-13. Available online: http://pareonline.net/getvn.asp? $\mathrm{v}=14 \& \mathrm{n}=13$.

Shulman, L. (April 4, 2010). Doctoral education shouldn't be a marathon, Chronicle of Higher Education.

Schulman, L., Golde, C. M., Bueschel, A. C., \& Garabedian, K. J. (2006). Reclaiming education's doctorates: A critique and a proposal. Educational Researcher, 35(3), 25-32. https://doi.org/10.3102/0013189X035003025

Walker, G., Golde, C., Jones, L., Bueschel, A., \& Hutchings, P. (2008). The formation of scholars: Rethinking doctoral education for the twenty-first century. San Francisco, CA: Jossey-Bass.

Winter, R., Griffiths, M., \& Green, K. (2000). The 'academic' qualities of practice: What are the criteria for a practicebased PhD? Studies in Higher Education, 25(1), 25-32. 